\title{
A influência dos vínculos organizacionais na consolidação dos Centros de Atenção Psicossociais
}

\author{
The influence of organizational ties \\ in the consolidation of Psychosocial Care Centers
}

Haiana Maria de Carvalho Alves ${ }^{1}$

Lidiane Bento Ribeiro Dourado ${ }^{1}$

Verônica da Nova Quadros Côrtes ${ }^{1}$

${ }^{1}$ Colegiado de Psicologia,

Universidade Federal do

Vale do São Francisco.

Av. José de Sá Maniçoba S/N,

Centro. 56.304-917

Petrolina PE.

haycarvalho@yahoo.com.br

\begin{abstract}
This article seeks to investigate the influence of organizational ties in the consolidation of Psychosocial Care Centers (CAPS - II and AD [Alcohol and Drugs]) in the city of Petrolina, State of Pernambuco, Brazil. Based on qualitative research, semi-structured interviews were conducted with a multi-professional team from both CAPS, with the sample consisting of one representative from each professional category. A critical review of the data was based on content analysis prepared from categorization of the discourses. The results showed that, in general, the teams do not possess sufficient theoretical knowledge about the system of which they are part. Moreover, although there is a high level of satisfaction, precarious working conditions and a lack of professional recognition and labor input can negatively affect the institutional dynamics. Lastly, a quantitative equivalence was also detected regarding affective and calculative aspects of organizational commitment and a close relationship between length of service and involvement with the work.

Key words Organizational ties, Psychosocial care center, Mental health
\end{abstract}

Resumo O presente trabalho teve como objetivo investigar a influência dos vínculos organizacionais na consolidação dos Centros de Atenção Psicossocial (CAPS) II e AD da cidade de Petrolina $(P E)$. Entrevistas semiestruturadas foram realizadas com 18 membros da equipe multiprofissional de ambos os CAPS, sendo a amostra constituida por um representante de cada categoria profissional. A apreciação crítica dos dados baseouse em análise de conteúdo elaborada a partir de categorizações dos discursos. Os resultados evidenciaram que, de modo geral, as equipes não possuem um conhecimento teórico suficiente sobre o sistema no qual estão inseridas. Além disso, embora haja um alto indice de satisfação, as precárias condições de trabalho, como a falta de reconhecimento profissional e insumos de trabalho, acabam afetando esta dinâmica institucional. Por fim, foi verificada também uma equivalência quantitativa referente aos aspectos afetivo e calculativo do comprometimento organizacional e uma estreita relação entre tempo de serviço e envolvimento com o trabalho.

Palavras-chave Vinculos organizacionais, Centro de Atenção Psicossocial, Saúde mental 


\section{Introdução}

A prática em saúde mental exige do profissional uma visão abrangente de aspectos sociais e políticos e inclui, entre outras coisas, o conhecimento teórico que embasa sua prática, o vínculo destes em relação ao trabalho desempenhado e a percepção de suporte e reciprocidade acerca da instituição de trabalho. Além disso, o conceito de loucura, os modos de perceber e lidar com esta realidade também podem interferir no cotidiano de trabalho em saúde mental e contribuir para a concretização de mudanças no paradigma sociocultural desta área.

No entanto, no decorrer dos últimos séculos, o tratamento em saúde mental nem sempre empregou um olhar centrado na pessoa que carrega algum sofrimento psíquico, sendo esta inicialmente estigmatizada como louca "errante", perpassando pela doente mental, até ao que hoje em dia se intitula, embora ainda sem consenso, como pessoa com sofrimento psíquico. De qualquer modo, o internamento sempre foi o principal recurso utilizado como meio de tratamento para a loucura.

$\mathrm{Na}$ Idade Clássica, o internamento era baseado em uma prática de 'proteção' e guarda, como um jardim das espécies, caracterizando-se como um tratamento moral, sem depender de uma ciência médica. Posteriormente, o início do século XVIII foi marcado pela convergência entre percepção, dedução e conhecimento, ganhando o internamento características médicas e terapêuticas e o sujeito sendo encaixado em categorias e nomenclaturas gerais.

Consequentemente, na segunda metade do século XVIII, a desrazão, gradativamente, foi perdendo espaço e a alienação agora ocupa o lugar como critério de distinção do louco ante a ordem social ${ }^{1}$. Isto vem corroborar com a ideia de estigmatização da loucura, quando propõe uma "proteção" por meio dos internamentos e, a posteriori, uma ordem social, resultando na exclusão em asilos e hospitais sem as mínimas condições de saúde, higiene e cuidado.

Durante muito tempo, não houve políticas públicas na saúde para amparar e proteger as pessoas com algum sofrimento psíquico, desta maneira, estes indivíduos eram privados de todos os seus direitos. Essa lógica de preconceito e exclusão transcorreu várias gerações e o internamento psiquiátrico foi, por um longo período, o recurso mais utilizado.

Assim, a dinâmica da reforma psiquiátrica teve ampla repercussão e trouxe propostas de cuida- do substitutivas a esse modelo manicomial. Por se tratar de um processo que ainda está em movimento, a consolidação desses novos ideais está imbricada em diversos fatores que vêm sendo gradativamente ressignificados e depende, direta e indiretamente, da solidificação das políticas públicas em saúde mental, bem como de uma transformação cultural e social acerca do sofrimento psíquico.

\section{Reforma psiquiátrica e política nacional de saúde mental}

A reforma psiquiátrica no Brasil teve início com a crise da Divisão Nacional de Saúde Mental (DINSAM), resultado de reivindicações dos trabalhadores da área de saúde mental por melhores condições de trabalho. A repercussão alcançada por este movimento culminou em vários debates e discussões sobre o tema, gerando novas propostas e consequentes mudanças na atenção à saúde, em especial à mental.

Além disso, fomentou novos olhares para as questões de cidadania, do cuidado e da qualidade de vida das pessoas que sofrem com algum transtorno psíquico, estimulando discussões e políticas públicas sobre a desinstitucionalização, que se configura enquanto instrumento de desconstrução dos dispositivos institucionais ${ }^{1}$.

Em outras palavras, a reforma se configura como processo político e social complexo, composto de atores, instituições e forças de diferentes origens, e que incide em territórios diversos, nos governos federal, estadual e municipal, nas universidades, no mercado dos serviços de saúde, nos conselhos profissionais, nas associações de pessoas com transtornos mentais e de seus familiares, nos movimentos sociais e nos do imaginário social e da opinião pública² ${ }^{2}$.

Historicamente, dois momentos tiveram grande importância neste cenário de mudança da área de saúde: a Constituição de $1988^{3}$ e a Lei $10.216 / 01^{4}$. Dentre as implantações decorrentes da Constituição Federal de $1988^{3}$, destaca-se a criação do Sistema Único de Saúde (SUS), visando a garantir o acesso à saúde enquanto direito de todos, uma transformação significativa que preconizou inúmeras políticas públicas, inclusive na saúde mental.

Outro fator importante ocorreu no ano de 1989, ocasião em que o então deputado Paulo Delgado propôs uma lei priorizando uma reorientação do modelo assistencial, substituindo o modelo manicomial asilar. Porém, esta lei só veio a ser aprovada em 06 de abril de 2001, ficando conheci- 
da como Lei Paulo Delgado ou Lei 10.2164. Ambos os processos contribuíram para que houvesse uma ampliação e acessibilidade aos serviços em saúde, além de uma ruptura, embora gradual, na maneira de apreender o sujeito em seu sofrimento.

Posteriormente, este modo de apreender o sujeito seria embasado na concepção de acolhimento e cuidado integral. Segundo Souza et al. ${ }^{5}$, o acolhimento deve ser visto como um dispositivo potente para atender à exigência de acesso; propiciar vínculo entre equipe e população, trabalhador e usuário; questionar o processo de trabalho; desencadear o cuidado integral e modificar a clínica. O cuidado integral surge como um dos desafios da prática em saúde e pode ser compreendido como um conjunto de ações que visa a abarcar o indivíduo de forma plena, através de atitudes acolhedoras por parte dos profissionais da área e responsabilização dos indivíduos diante dos seus problemas.

É nesse contexto de mudanças que surge a Política Nacional de Saúde Mental (PNSM), resultado de um processo articulado nos campos técnico-assistencial, político-jurídico, teóricoconceitual e sociocultural, que vem propor a desinstitucionalização através de uma redução gradual dos leitos psiquiátricos, da efetivação destes em hospitais gerais e da criação de hospitais-dia com o intuito de deslocar o foco para uma rede de cuidado integrada.

A ampliação dessa rede aponta também a importância de uma maior articulação com a atenção básica e com outros setores sociais, a fim de proporcionar a inclusão social, cultural e de trabalho. Dentre os dispositivos de saúde mental que integram a nova proposta de cuidado, a PNSM aponta a expansão e qualificação dos Centros de Atenção Psicossociais (CAPS), serviço este que será detalhado a seguir.

\section{Centros de atenção psicossocial (CAPS)}

O presente trabalho priorizou o CAPS, que se constitui como um serviço de apoio e referência às pessoas que sofrem algum tipo de transtorno psíquico. Vinculada ao SUS, esta instituição se configura como um modelo substitutivo dos hospitais psiquiátricos, de acordo com a Portaria de no $336 / \mathrm{GM}$, de 19 de fevereiro de $2002^{6}$. Esta portaria redireciona o modelo assistencial em saúde mental, estabelecendo a quantidade de profissionais nestes serviços de acordo com a demanda municipal, bem como quais são as atividades que devem ser ofertadas e supervisionadas nestas instituições.
Desse modo, os CAPS configuram-se como serviços comunitários ambulatoriais e regionalizados, nos quais os pacientes deverão ter acesso a consultas médicas, visitas domiciliares, atendimentos terapêuticos individuais e/ou grupais. Além disso, podem participar de ateliês abertos, de atividades lúdicas e recreativas promovidas pelos profissionais do serviço, de maneira mais ou menos intensiva e articulada em torno de um projeto terapêutico individualizado, voltado para o tratamento e a reabilitação psicossocial, devendo também haver iniciativas extensivas aos familiares e às questões de ordem social presentes no cotidiano dos usuários ${ }^{7}$.

De acordo com o Ministério da Saúde, existem cinco tipos de CAPS, que correspondem a demandas e tratamentos especializados. Os CAPS I, II e III, por exemplo, referem-se ao atendimento de pessoas com transtornos mentais severos $\mathrm{e}$ persistentes. O que irá diferenciá-los no momento da implantação será a quantidade de habitantes em cada território. O CAPS I integra ações voltadas para crianças e jovens e o CAPS AD atende usuários de álcool e outras drogas.

É válido ressaltar que, embora o CAPS III seja o único que funciona diariamente em tempo integral, possuindo leitos para acolhimento noturno, ele não se equipara ao conceito de internação hospitalocêntrica. Este serviço se dispõe a atender demandas mais graves, que possam vir a necessitar deste apoio, com um limite de atendimento por usuário, dentro do prazo de um mês, sem perder o foco do tratamento destes serviços, que está no convívio social.

Dentro do CAPS existem três modalidades de atendimento ao usuário: intensivo, semi-intensivo e não intensivo, que correspondem à frequência ao serviço referente a todos os dias da semana, duas ou três vezes por semana e até duas vezes por mês, respectivamente. Logo após a entrada do usuário no serviço, deve ser realizado um Projeto Terapêutico Singular (PTS), que se caracteriza como um conjunto de propostas e condutas terapêuticas articuladas para um sujeito individual ou coletivo, resultado da discussão coletiva de uma equipe interdisciplinar, com apoio matricial se necessário ${ }^{8}$.

A equipe do CAPS geralmente inclui psiquiatras, psicólogos, pedagogos, assistentes sociais, terapeutas ocupacionais, enfermeiros, técnicos de enfermagem, técnicos administrativos, auxiliares de serviços gerais, vigilantes, técnicos educacionais e artesãos, podendo haver variações em cada tipo de serviço, segundo a demanda de cada instituição. 
Considerando essa relação de profissionais, a Portaria n³36/02 ${ }^{6}$ estabelece que o CAPS II e o CAPS AD devem conter 12 e 13 profissionais, respectivamente, para atender, no máximo, 45 usuários em regime intensivo por dia, ou seja, que frequentam o serviço entre 3 e 5 dias por semana.

A proposta dos CAPS inclui tanto a participação do usuário no seu tratamento, opinando junto à equipe ou ao profissional de referência do serviço, quanto à articulação entre os membros da equipe de saúde entre si e com a rede. $\mathrm{O}$ profissional deve conhecer as reais necessidades dos usuários, utilizando, entre outros instrumentos, visitas domiciliares como mais um recurso de estreitamento de vínculo e efetivação do elo entre o serviço e a comunidade.

A responsabilidade social da equipe de saúde mental perante os usuários e a instituição como um todo representa a base para a operacionalização de uma mudança efetiva no panorama da saúde. É necessário que haja um maior engajamento dos profissionais com o trabalho em saúde mental, mais especificamente nesse contexto de atenção psicossocial. Assim, deve haver, além de satisfação, envolvimento e comprometimento com o trabalho e com os pressupostos da instituição; condições de trabalho favoráveis para a realização das atividades cotidianas, tais como recursos materiais e insumos básicos, além do reconhecimento profissional.

\section{Vínculo organizacional}

Segundo Siqueira e Gomide Júnior ${ }^{9}$, as relações de trabalho preconizam uma disposição por parte do empregado e do empregador em estabelecer vínculos, além de poder indicar o comportamento desse funcionário frente à organização. Conforme definem Kramer e Faria ${ }^{10}$, vínculo é uma estrutura na qual estão incluídos um indivíduo, um objeto e uma relação particular entre eles - do indivíduo ante o objeto e viceversa -, ambos cumprindo determinada função.

Com o intuito de facilitar a compreensão das relações de trabalho em equipes de saúde, é pertinente contextualizar o conceito de vínculo organizacional que, segundo pressupostos psicossociais, abarca a satisfação e o envolvimento com o trabalho, e o comprometimento com a organização, incluindo neste construto as percepções de justiça, suporte e reciprocidade organizacional.

Partindo da interpretação individual dos funcionários acerca da instituição à qual estão vinculados, Robbins ${ }^{11}$ aponta que esta percepção baseia-se no modo como esse sujeito apreende as relações do seu contexto, e não necessariamente significa a realidade em si. Já a justiça organizacional, que se caracteriza como um requisito básico para a compreensão das trocas, sejam econômicas ou sociais, que ocorrem nas relações entre os trabalhadores e suas organizações, não foi objeto de estudo nesta pesquisa.

A percepção de suporte organizacional significa o quanto o funcionário acredita que a instituição oferece um apoio em relação às políticas de gestão de pessoas. Esta percepção configurase como crenças globais acerca de o quanto o empregador cuida do bem-estar e valoriza as contribuições de seus empregados ${ }^{9}$.

A percepção de reciprocidade organizacional, por sua vez, está relacionada a uma troca de benefícios, que se configura como retribuição moral de favores. Se, em um momento, o empregado presta favores em benefício da instituição, pressupõe-se que, posteriormente, a instituição deverá agir em prol desse funcionário. Assim, tendo este sido doador para a organização no passado, a norma de reciprocidade permitiria ao empregado acreditar que, no futuro, a organização devedora retribuiria seus gestos sociais de ajuda quando ocorressem situações problemáticas em sua vida pessoal e/ou profissional ${ }^{9}$.

Portanto, a forma como o profissional percebe as relações dentro do seu contexto de trabalho e como interpreta a disponibilidade da instituição em retribuir suas atitudes em favor desta, tende a afetar o seu nível de comprometimento com o trabalho e com a organização. Deste modo, em relação ao conceito de comprometimento, embora não haja uma concordância universal entre os diversos estudos no que concerne à sua natureza, foi considerada nesta pesquisa a sua definição multidimensional. Assim, foram considerados os três componentes propostos por Allen e Meyer: afetivo, calculativo ou instrumental e normativo ${ }^{12}$.

O comprometimento afetivo refere-se a uma identificação com o trabalho, cujo foco está no desejo de permanecer vinculado, contribuindo com a organização. A dimensão calculativa diz respeito a trocas econômicas, ou seja, a uma avaliação acerca das perdas e ganhos, entre investimentos e danos associados a um possível rompimento com a instituição. O comprometimento normativo, por sua vez, refere-se a uma espécie de obrigação moral, uma retribuição de favores, relacionado a trocas sociais.

Vale ressaltar que, no que concerne ao ambiente de trabalho, essas três dimensões podem estar associadas, já que pode haver mais de uma razão 
para o sujeito se sentir comprometido com a organização. Em outras palavras, estas três variáveis podem aparecer simultaneamente, constituindo um sentido singular de comprometimento para cada funcionário.

Em relação à satisfação, o conceito foi considerado de modo multidimensional, incluindo os componentes afetivos que o integram. Assim, a satisfação no trabalho é entendida como uma produção subjetiva, elaborada a partir da avaliação do trabalhador em relação ao ambiente de trabalho, sendo atravessada por elementos intrínsecos e extrínsecos ao cotidiano do traba1 ho ${ }^{13}$. Em outras palavras, o trabalhador tende a se sentir satisfeito quando suas necessidades estão sendo supridas pela organização a partir do desempenho de sua função.

O conceito de envolvimento utilizado nesta pesquisa pode ser definido como o grau de identificação psicológica da pessoa com seu trabalho e a importância deste para a autoimagem ${ }^{9}$. Logo, a partir desta relação com a função desempenhada, alguns fatores podem funcionar como antecedentes do envolvimento, como características de personalidade, identificação com a tarefa, ou ainda, diálogo e participação nas decisões.

Considerando que o conceito de vínculo organizacional, segundo Kramer e Faria, denota a ligação do indivíduo com a organização e o envolvimento com seus projetos e objetivos, assim como o comprometimento com seus problemas, políticas, desempenhos e resultados ${ }^{10}$, parte-se do suposto de que indivíduos envolvidos, satisfeitos e comprometidos tendem a se sentir vinculados à instituição e ao trabalho.

Assim, o objetivo deste trabalho foi identificar as influências desses vínculos organizacionais na consolidação dos CAPS II e AD da cidade de Petrolina (PE), visto que estes são os principais serviços de referência no cuidado em saúde mental desta cidade. Concomitante a isso, pretendeu-se desvelar como se dá a relação que estas equipes estabelecem com sua prática, no intuito de corroborar ou ignorar as propostas advindas da PNSM, considerando o envolvimento e a satisfação com o trabalho e o comprometimento com a instituição.

\section{Método}

A presente pesquisa foi realizada nos CAPS II e $\mathrm{AD}$ da cidade de Petrolina (PE). Foram entrevistados nove funcionários de cada instituição, um de cada categoria profissional que compõe a equi- pe multiprofissional. À época da coleta, esse número equivalia a mais da metade dos funcionários de cada CAPS.

Este trabalho constitui-se uma investigação qualitativa que, segundo Minayo ${ }^{14}$, se aplica ao estudo da história, das relações, das representações, das crenças, das percepções e das opiniões, produtos das interpretações que os humanos fazem a respeito de como vivem, constroem seus artefatos e a si mesmos, sentem e pensam.

Em relação aos objetivos investigados, o trabalho configurou-se como uma pesquisa exploratória, que se caracteriza como uma forma de aprimorar ideias ou descobertas de intuições ${ }^{15}$. Os dados foram coletados em campo, enfatizando a situação tal como ocorre através da observação direta. Posteriormente, utilizou-se a análise de conteúdo, empregando a categorial temática, que se configura como uma organização de ideias que facilitam a categorização, promovendo a atribuição de significados ou mesmo interpretar a realidade pesquisada.

Como estratégia de levantamento de dados foi realizada uma entrevista semiestruturada, considerando os aspectos subjetivos relacionados à prática de cada sujeito. Dentre estes, destacam-se a percepção pessoal acerca do trabalho e da relação com os colegas e superiores, o conhecimento sobre a dinâmica do CAPS como um dispositivo de atenção em saúde mental, bem como as mobilizações sociais e políticas que o antecederam, além do envolvimento, satisfação e comprometimento com o trabalho e com a instituição de modo geral.

Para tanto, a priori, os participantes assinaram o Termo de Consentimento Livre e Esclarecido (TCLE). O gravador foi utilizado com o intuito de que nenhuma informação fosse perdida, sendo garantido o sigilo em relação às opiniões pessoais. Para auxiliar este processo, a entrevista foi realizada em um ambiente físico favorável, a fim de evitar interrupções. Vale ressaltar que este trabalho foi submetido e aprovado pelo Comitê de Ética da Universidade Federal do Vale do São Francisco.

Após a coleta de dados, as entrevistas foram transcritas, analisadas e interpretadas seguindo a análise de conteúdo que, para Bardin ${ }^{16}$, significa um conjunto de técnicas de análise das comunicações. Destarte, o material transcrito foi analisado, considerando os temas que surgiram com maior frequência e organizados posteriormente em categorias, conforme suas congruências semânticas. Desse modo, o conteúdo das entrevistas foi dividido em quatro categorias, sendo elas: 
conhecimento sobre a política de saúde mental, condições de trabalho, identificação com a área de saúde mental e reconhecimento profissional.

\section{Resultados e discussões}

\section{Conhecimento sobre a política de saúde mental}

Em relação ao entendimento sobre a reforma psiquiátrica foi possível perceber que houve uma grande prevalência, entre os entrevistados, no que condiz à falta de uma opinião clara sobre o que representa este movimento, enfocando mudança apenas no lócus da instituição, sem deixar claro o que isso representa. Um dos entrevistados comenta: Olha aí... não sei não. A psiquiatria mudou, antes era mais manicômio, era vista de outra maneira, era sanatório mesmo, como dizem (Ent. 02).

No que diz respeito aos internamentos psiquiátricos, houve divergência de opinião. Parte dos entrevistados coloca-se a favor do internamento, considerando que a demanda familiar muitas vezes predomina na busca por esse tipo de intervenção, como mostra a seguinte fala: Acho que pode ser bom, mas é melhor para o familiar do que para o paciente porque o familiar muitas vezes quando o paciente está em crise, ele está se sentindo ameaçado e aí o internamento vem trazer essa ajuda, é um caminho (Ent. 04).

Outra parte da amostra ressalta que, a depender da situação, este tipo de tratamento é uma alternativa, como em casos de agressividade ou risco de vida para o paciente ou para outros, conforme é exemplificado a seguir: Em alguns casos é necessário sim, porque tem pacientes que dentro de casa estão causando transtornos, até com risco de morte para a família, pra sociedade, aí eu acho que tem que internar um tempinho, pra recuperar (Ent. 05).

Há ainda discursos afirmando que, embora sejam necessários em alguns casos, os internamentos não são favoráveis, podendo resultar numa piora clínica e no retorno do paciente mais prejudicado ao âmbito social: Eu acho que ainda são necessários, mas as condições que existem hoje não são favoráveis para uma melhora clinica (Ent. 03).

De acordo com esses relatos, ao concordar com a aplicação dos internamentos psiquiátricos, os funcionários estão refutando o que a Lei 10.216 de abril de $2001^{4}$ prevê em seu artigo $4^{\circ}$ : a internação, em qualquer de suas modalidades, só será indicada quando os recursos extra-hos- pitalares se mostrarem insuficientes, ou seja, quando as ações preventivas de cuidado não suprirem a demanda desses indivíduos. Vale ressaltar que existem os casos de internação voluntária, previstos nesta mesma lei, em seu artigo $7^{\circ}$, quando a opção por este tipo de tratamento parte do consentimento do próprio usuário.

No que concerne ao conhecimento sobre a PNSM, um número considerável de funcionários não tem informação suficiente a respeito, limitando-se a pontuar que existe muito discurso e pouca funcionalidade. A seguinte fala confirma esta afirmativa: Assim como outras politicas, ela também é ainda tímida na ação; no papel, a legislação é ótima, mas a gente ainda deixa uma lacuna muito grande entre o que eu faço e o que está na lei (Ent. 06).

Quando questionados acerca dos objetivos do CAPS, houve uma grande incidência dos relatos se referindo à sua função social, abarcando pacientes egressos de internamentos, pacientes em crise, dependentes químicos ou depressivos e reinserindo-os na sociedade. Isso pode ser comprovado através do discurso de um dos funcionários: Eu acho que é cuidar para reinserir os pacientes na sociedade, que tem muito preconceito e acima de tudo, eu acho, que é levantar o astral [...] a gente tenta (Ent. 01). Este dado reforça um dos princípios básicos do centro de atenção psicossocial que inclui, entre outras coisas, a reinserção social do indivíduo através do acesso ao trabalho, lazer, exercício dos direitos civis e fortalecimento dos laços familiares e comunitários ${ }^{17}$.

Os resultados evidenciaram que, em um dos CAPS pesquisados, há muita procura apenas por atendimento psiquiátrico, gerando uma superlotação no serviço com características ambulatoriais. Embora alguns funcionários tenham apontado como uma possível causa para tanto o déficit do município em relação à oferta de atendimento psiquiátrico, essa demanda restrita ao médico vai de encontro à integralidade proposta pelos CAPS.

Em linhas gerais, foi possível observar que os profissionais de ambas as equipes detêm um conhecimento técnico relativo à sua área de formação e atuação, porém nem todos demonstram uma compreensão clara e aprofundada sobre a complexidade do trabalho em uma rede de atenção em saúde mental, como é o caso do CAPS.

\section{Condições de trabalho}

Entre as dificuldades encontradas em seus respectivos contextos de trabalho foi assinalada, 
de forma predominante, a falta de profissionais para dar o suporte necessário à atual demanda desse tipo de serviço: Poderíamos contribuir mais, mas existem coisas estruturais que não dependem da gente, como a contratação de oficineiros, e isso inviabiliza porque você desloca profissionais de nivel superior para desenvolver trabalhos que podem ser feitos por técnicos e isso prejudica muito. Acho que hoje a gente cumpre o papel, mas podia ter uma eficácia muito maior (Ent. 16).

De modo semelhante, consideram a equipe de trabalho pequena quando comparada à quantidade de usuários que o serviço comporta, acarretando em acúmulo de função. Isto pode ser evidenciado através da fala de um dos sujeitos entrevistados quando perguntado sobre sua função dentro do serviço: Qual deles? [risos] Mulher, o meu cargo no CAPS é [profissional de nível fundamental], só que quando a demanda é demais, tem que ir, vai entrando nos setores, [...] e o pior de ainda ter que prestar socorro, é ter que fazer a minha, a minha tarefa [...] é desse jeito (Ent. 01)

De modo geral, o que ficou exposto nos discursos dos funcionários é que, apesar de trabalharem de forma articulada, eles estão sobrecarregados devido à demanda excessiva de usuários e à falta de profissionais, ou seja, estando a equipe incompleta, todos cooperam para o andamento do serviço, mas mesmo assim ainda não é o suficiente.

Logo, é importante diferenciar a integralidade nos serviços de saúde e a sobrecarga de trabalho. A PNSM enfatiza a importância da interdisciplinaridade, no sentido de não reduzir a atuação dos profissionais às atividades características de sua formação, preconizando uma articulação da equipe e evitando a fragmentação da atenção ao indivíduo. O déficit na quantidade de funcionários que acarreta na sobrecarga, por sua vez, parece ser um problema de outra ordem, mais ligada à gestão.

Nas instituições pesquisadas, o número de profissionais em cada equipe atualmente é inferior ao limite mínimo determinado pela Portaria $n^{\circ} 336 / 02^{6}$, que redireciona o modelo assistencial em saúde mental. Existem atualmente 15 profissionais no CAPS II para atender uma demanda de aproximadamente 75 usuários e 14 funcionários no CAPS AD para atender 60 usuários, ambos na modalidade intensiva, conforme dados administrativos de ambos os serviços, indicando incoerência entre o que deveria acontecer e o que realmente ocorre nesses contextos.

Este dado pode ser confirmado por meio do discurso de um dos entrevistados: Aqui a gente é só pra atender 220 pacientes e a gente já tá chegando a quase 520 pacientes, então, não tem alimentação e medicação que dê jeito (Ent. 07). Isto representa um déficit estrutural e funcional e tende a afetar a qualidade do atendimento prestado, visto que existe uma grande demanda para uma quantidade insuficiente de profissionais atuando no serviço, de alimentação e de medicação disponíveis.

Quando foi investigado qual era a relação que os funcionários estabeleciam com os colegas e superiores, houve uma prevalência de respostas referentes ao diálogo como alternativa para resolver as situações dentro da equipe. Este conteúdo denota um fator positivo uma vez que, para que o trabalho em equipe seja viabilizado, há a necessidade de uma consonância entre os trabalhadores, mediada pela troca de conhecimentos e articulação de um "campo de produção do cuidado" comum a todos ${ }^{18}$. Este fator aponta para uma relação entre o trabalho em equipe e a satisfação, já que o que é construído no contexto de trabalho tende a interferir de modo substancial na atuação dos profissionais, bem como na interação e nas trocas estabelecidas entre eles.

Além disso, diante de algum problema no serviço, administrativo ou clínico, a grande parte dos profissionais afirmou recorrer aos colegas ou superiores: procuro resolver, né? quando o paciente está em crise, eu tento chamar um técnico, né? Chamo um técnico para atender, né? Nas outras questões, eu passo pra coordenadora (Ent. 01). Essa atitude frente a uma eventual dificuldade pode revelar um envolvimento com o trabalho, mas não um comprometimento com a instituição, visto que eles demonstram realizar efetivamente o seu trabalho, mas não se sentem estimulados a ultrapassar o que lhe concerne à sua função, ou seja, a atuação da equipe nem sempre é multidisciplinar.

\section{Identificação com a área de saúde mental}

Uma parcela significativa dos funcionários, antes de vincular-se ao CAPS, não conhecia o serviço ou não tinha afinidade com a proposta. A princípio, o trabalho nessa instituição foi visualizado tanto como uma possibilidade de expansão do conhecimento e de crescimento profissional, quanto uma oportunidade de emprego: Agora é porque eu gosto, antes era porque eu precisava. A convivência fez mudar, o convívio com os pacientes, né? com os outros profissionais (Ent. 01). Este tipo de relato aponta para uma possível relação entre tempo de serviço e envolvimento com o trabalho. Segundo Martins et al. ${ }^{19}$, a experiência 
profissional, o envolvimento institucional e a estabilidade adquirida pelo tempo de serviço são fatores que estimulam nos profissionais a permanência em uma organização.

Assim, boa parte dos sujeitos entrevistados afirmou que desempenha seu trabalho por prazer, se sente satisfeita e possui uma boa dinâmica com seus colegas e superiores, o que pode sugerir, além de boas relações de trabalho, um melhor desempenho dentro da equipe. No entanto, dentre estes, mais da metade evidenciou que as condições de trabalho não são favoráveis, devido à carência de profissionais, de recursos financeiros e de reconhecimento profissional: De trabalhar em CAPS me sinto satisfeita, mas de trabathar nessas condições me sinto frustrada porque falta tudo, recursos humanos, aqui a gente não tem nem $50 \%$ da equipe mínima preconizada pela portaria. Falta de insumos para as oficinas, alimentação, então assim, diante de toda crise que existe, a gente podia estar passando por uma situação menos desagradável (Ent. 02).

Isso demonstra que o elo entre trabalho e satisfação está relacionado também a fatores extrínsecos, como as condições laborais, que acabam influenciando diretamente o funcionamento de ambas as instituições. Assim, apesar de satisfeitos, há um sentimento de frustração causado pela percepção da falta de suporte organizacional, o que pode afetar o nível de comprometimento com a organização.

Referente a esse assunto, Siqueira e Gomide Júnior $^{20}$ afirmam que quanto mais os empregados percebem o suporte da organização, mais se comprometem com ela. Deste modo, pode-se compreender que a percepção de suporte organizacional favorece o desencadeamento de compromissos afetivos com a organização.

Um fator interessante para esta pesquisa foi que parte significativa dos entrevistados já havia tido experiências anteriores com a área de saúde mental, seja na formação acadêmica ou no campo de atuação profissional. Este fato pode ter influenciado na escolha da instituição e permanência na mesma, se considerarmos que, quando questionados sobre a sua identificação com a área de saúde mental, numa escala de 0 a 10 , a média de respostas correspondeu a 8,5.

Em relação ao comprometimento organizacional, foi verificada uma equivalência nos aspectos afetivo e calculista. Por um lado, eles se mantêm afiliados à organização por se identificar com o trabalho que realizam, porém, também existe um componente avaliativo sobre vantagens e desvantagens em permanecer na insti- tuição, considerando a falta de recursos para o desenvolvimento dos trabalhos e de investimento em recursos humanos.

\section{Reconhecimento profissional}

Em relação ao reconhecimento profissional, ficou evidente que não há uma preocupação por parte da gestão em investir na qualificação dos funcionários, nem em capacitações, nem em educação permanente. Isso contraria a sugestão de Ceccim $^{21}$ de que a educação permanente em saúde constitui estratégia fundamental para as transformações do trabalho no setor para que venha a ser lugar de atuação crítica, reflexiva, propositiva, compromissada e tecnicamente competente. Este investimento pode ser considerado como fundamental na saúde, em especial na mental, pois os processos de mudanças são contínuos, exigindo uma reavaliação permanente dos funcionários perante sua prática.

Os funcionários que estão no serviço há mais tempo relatam que, na implantação dos CAPS em Petrolina (PE), foi ofertada apenas uma capacitação para ambas as equipes, mas nada neste sentido voltou a ser oferecido: Nós todos tivemos uma capacitação no início do CAPS, mas assim era pra ter todo ano, mas nunca mais teve não. Acho importante pra aprendizagem, que a gente nunca sabe tudo (Ent. 01).

Esse déficit de investimento na qualificação do funcionário tem gerado uma insatisfação coletiva com as condições de trabalho oferecidas pela organização, resultando na falta de percepção de suporte organizacional, uma vez que quase todos os profissionais que atuam hoje nos CAPS não receberam nem esse acompanhamento inicial. Percebe-se, portanto, uma despreocupação da gestão com o investimento permanente de formação de profissionais para a saúde mental, conforme aponta a PNSM.

Considerando essa ausência de oferta de investimento profissional, um número restrito de funcionários busca especialização por conta própria, ou seja, investe na sua formação a fim de adquirir e/ou ampliar o seu conhecimento profissional e, consequentemente, a qualidade do serviço prestado na área, como relata este sujeito: Faço especialização em saúde mental e atenção psicossocial. Eu pago (Ent. 03). Este fato dificulta a percepção de reciprocidade por parte do funcionário, pois o mesmo se percebe contribuindo com o trabalho dentro da organização sem receber, no entanto, investimentos para o seu desenvolvimento profissional. 
Vale ressaltar que houve uma discrepância nos resultados das duas instituições investigadas no que se refere à disponibilidade da gestão municipal em acatar a opinião dos funcionários e à articulação com outros setores sociais, embora ambas as equipes afirmem emitir suas opiniões sempre que julgam necessárias em assuntos referentes ao trabalho e à organização como um todo. Enquanto um dos serviços revela essa abertura da chefia para acatar as opiniões, no outro contexto, foi demonstrada a sua inexistência, sendo assinalado que as decisões não são compartilhadas com os demais membros da equipe: $E u$ dou minha opinião, às vezes é acatada, mas às vezes as decisões já vêm de lá de cima (Ent. 02).

Essa desarticulação contraria a base da proposta de trabalho em equipe, onde a interdisciplinaridade é a primeira exigência de comunicação, ou seja, o diálogo entre os saberes deve acontecer de modo construtivo. Se cada ciência possui lógica própria, a compreensão desse pluralismo é essencial para uma inteligibilidade diferente ${ }^{22}$.

De modo semelhante, em relação à articulação com outros setores sociais, enquanto em um dos serviços foi verificada a existência de parcerias, no outro contexto foi percebido um déficit nessa articulação. Isto pode ser explicitado em uma das falas: Nós tínhamos uma comunicação maior e mais efetiva com a atenção básica, tivemos qualificação da equipe, então houve momentos de maior integração com a rede. Nós tínhamos também apoio grande da gerência de saúde mental do estado [...] hoje a gente não tem mais apoiador (Ent. 06).

A desarticulação entre a gestão estadual e municipal demonstra uma falta de estreitamento de vínculos que vai de encontro à proposta dos CAPS de ultrapassar a própria estrutura física em busca de uma rede de suporte social, potencializadora de suas ações, preocupando-se com o sujeito e a singularidade, sua história, sua cultura e sua vida cotidiana ${ }^{17}$. Assim, esta falha na articulação da gestão com os demais dispositivos sociais tende a inviabilizar o andamento e a manutenção das atividades propostas pela PNSM, que abarca, entre outras coisas, um diálogo entre a saúde mental e a atenção básica e programas permanentes de formação de profissionais de saúde mental.

\section{Considerações finais}

O profissional de saúde mental é de fundamental importância no processo de consolidação dos pressupostos desse modelo substitutivo. Para tanto, é importante que ele tenha conhecimento acerca dos movimentos e políticas que embasam suas práticas. Além disso, é necessário também que a instituição viabilize boas condições de trabalho para que se estabeleçam bons vínculos organizacionais, pautados na identificação e no compromisso com a área de saúde mental e com o trabalho. Por fim, o reconhecimento profissional tende a possibilitar melhores desempenhos, ou seja, condutas coerentes com o seu contexto de trabalho.

Esta pesquisa possibilitou identificar que a maioria dos funcionários entrevistados desconhece os conteúdos aprofundados sobre a reforma psiquiátrica, os internamentos psiquiátricos e a PNSM, mas reconhece as funções básicas do CAPS como a reinserção social e a integralidade no atendimento não restrito apenas ao atendimento psiquiátrico.

A maioria aponta que sua inserção profissional nesta instituição decorreu inicialmente por necessidade de emprego, mas que, com o tempo, a experiência de trabalho possibilitou o desenvolvimento de uma vinculação de caráter afetivo e envolvimento pessoal com o trabalho. Em outras palavras, embora a oportunidade de emprego tenha precedido o envolvimento, foi percebido que a maioria hoje desempenha sua função por prazer e se sente satisfeita, mantendo uma boa relação com os usuários do serviço, embora esteja exposta a condições de trabalho inapropriadas.

Outra dificuldade refere-se à sobrecarga de trabalho e ao acúmulo de função, devido a um número de funcionários inferior ao recomendado quando comparado à demanda de usuários. De modo geral, essa falta de investimento em recursos humanos afeta a percepção de suporte e reciprocidade organizacionais. Apenas na época da implantação destes serviços foi oferecida uma capacitação, porém hoje apenas uma minoria que participou de tal atividade continua trabalhando em tais instituições.

Por outro lado, alguns funcionários têm investido individualmente em sua carreira, fazendo cursos de aperfeiçoamento na área de saúde mental. Este fator confirma que há envolvimento e comprometimento afetivo com o trabalho desempenhado, porém não há o mesmo correlato com a organização devido à percepção de falta de suporte organizacional.

Além disso, vale ressaltar que esses funcionários trabalham diretamente com saúde mental e não possuem uma assistência voltada para sua 
própria saúde. O modo como a maioria está vinculada ao serviço, através de contratos, não permite certa estabilidade e benefícios trabalhistas como férias, plano de saúde, décimo terceiro salário, folga ou lazer, qualificação profissional, entre outros. De qualquer forma, este fator também aponta para uma falta de suporte organizacional existente na relação entre a equipe e a gestão.

Assim, percebeu-se que há envolvimento, satisfação e comprometimento afetivo com o trabalho. Estes componentes, quando bem articulados, tendem a melhorar o desempenho no trabalho, incidindo no prazer de atuar com comprometimento na instituição, propiciando um vínculo mais articulado. Este resultado corrobora os estudos realizados por Siqueira e Padovam ${ }^{23}$ sobre bem-estar subjetivo, psicológico e no trabalho, onde foi demonstrado que trabalhadores satisfeitos com o trabalho, envolvidos com suas tarefas e com compromisso afetivo com a organização possuem um elevado nível de bem-estar laboral.

De modo semelhante, algumas pesquisas indicam que o indivíduo satisfeito tende a manter em níveis altos o seu envolvimento com o trabalho que realiza e a se comprometer com a orga- nização que o emprega ${ }^{9}$. Porém, existe um comprometimento calculista com a instituição e a iminência de avaliar se deve ou não permanecer vinculado à mesma. Este fator se deve, entre outras coisas, à percepção de falta de suporte e reciprocidade organizacional.

Conclui-se que, no que se refere ao estabelecimento de vínculos dos funcionários com o trabalho que realizam, existem fortes indícios de envolvimento, satisfação e comprometimento. Porém, no que se refere aos vínculos com a organização, estes se encontram enfraquecidos pela falta de suporte e reciprocidade organizacional, o que pode prejudicar diretamente a consolidação dos Centros de Atenção Psicossocial.

As limitações deste estudo estão relacionadas, principalmente, às interrupções ocorridas durante duas entrevistas em uma das instituições, o que pode ter enviesado a resposta de dois sujeitos de pesquisa. Tendo em vista a complexidade inerente ao tema investigado, este trabalho remete à elaboração de novos estudos, tais como uma investigação acerca da saúde mental do trabalhador e o estabelecimento de vínculo organizacional segundo a perspectiva dos usuários do serviço.

\section{Colaboradores}

HMC Alves, LBR Dourado e VNQ Côrtes participaram igualmente de todas as etapas de elaboração do artigo. 


\section{Referências}

1. Amarante P. Revisitando os paradigmas do saber psiquiátrico: Tecendo o percurso do Movimento da Reforma Psiquiátrica. Loucos pela vida: a trajetória da reforma psiquiátrica no Brasil. 2a Edição. Rio de Janeiro: Fiocruz; 1995.

2. Brasil. Ministério da Saúde (MS). Secretaria de Atenção à Saúde. DAPE. Coordenação Geral de Saúde Mental. Reforma psiquiátrica e política de saúde mental no Brasil. Documento apresentado à Conferência Regional de Reforma dos Serviços de Saúde Mental: 15 anos depois de Caracas. Brasília: Organização Pan-americana de Saúde (OPAS); 2005.

3. Brasil. Constituição da República Federativa do Brasil de 1988. Diário Oficial da União 1988; 5 out.

4. Brasil. Ministério da Saúde (MS). Lei no 10.216, de 6 abril de 2001. Dispõe sobre a proteção e os direitos das pessoas portadoras de transtornos mentais e redireciona o modelo assistencial em saúde mental. Diário Oficial da União 2001; 9 abr.

5. Souza ECF, Vilar RLA, Rocha NSPDR, Uchoa AC, Rocha PM. Acesso e acolhimento na atenção básica: uma análise da percepção dos usuários e profissionais de saúde. Cad Saude Publica 2008; 24(1):100-110.

6. Brasil. Ministério da Saúde (MS). Portaria n. ${ }^{\circ} 336 /$ GM de 19 de fevereiro de 2002. Estabelece CAPS I, CAPS II, CAPS III, CAPS i II e CAPS ad II. Diário Oficial da União 2002; 20 fev.

7. Onocko-Campos RT, Furtado JP. Entre a saúde coletiva e a saúde mental: um instrumental metodológico para avaliação da rede de Centros de Atenção Psicossocial (CAPS) do Sistema Único de Saúde. Cad Saude Publica 2006; 22(5):1053-1062.

8. Brasil. Ministério da Saúde (MS). Secretaria de Atenção à Saúde. Núcleo Técnico da Política Naciona de Humanização. Clínica ampliada: equipe de referência e projeto terapêutico singular ampliado, equipe de referência e projeto terapêutico singular. 2a Edição. Brasília: MS; 2007.

9. Siqueira MMM, Gomide Júnior S. Vínculos do indivíduo com o trabalho e com a organização. In: Zanelli JC, Borges-Andrade JE, Bastos AVB, organizadores. Psicologia, Organizações e Trabalho no Brasil. Porto Alegre: Artmed; 2004. p. 300-328.

10. Kramer GG, Faria JH. Vínculos organizacionais. Rev. Adm. Pública 2007; 41(1):83-104.

11. Robbins SP. Comportamento organizacional. Percepção e tomada de decisões individual. Tradução técnica Reynaldo Marcondes]. 11 a Edição. São Paulo: Pearson Prentice Hall; 2005.

12. Bastos AVB, Siqueira MMM, Medeiros CAF, Menezes IG. Comprometimento Organizacional. In: Siqueira MMM. Medidas do Comportamento Organizacional: ferramentas de diagnóstico e de gestão. Porto Alegre: Artmed; 2008. p. 49-95.
13. Guimarães JMX, Jorge MSB, Assis MMA. (In) satisfação com o trabalho em saúde mental: um estudo em Centros de Atenção Psicossocial. Cien Saude Colet 2011; 16(4):2145-2154.

14. Minayo MCS. O desafio do conhecimento: pesquisa qualitativa em saúde. 10a Edição. São Paulo: Hucitec; 2007.

15. Gil AC. Como elaborar projetos de pesquisa. $4^{\mathrm{a}}$ ed. São Paulo: Atlas, 2002.

16. Bardin: L. Análise de conteúdo. Lisboa: Edições 70; 2010.

17. Brasil. Ministério da Saúde (MS). Secretaria de Atenção à Saúde. DAPE. Coordenação Geral de Saúde Mental. Saúde Mental e Atenção Básica: O vínculo e o diálogo necessários. [página na internet]. [acessado 2010 out 24]. Disponível em: http:// portal.saude.gov.br/portal/arquivos/pdf/ diretrizes.pdf

18. Araujo MBS, Rocha PM. Trabalho em equipe: um desafio para a consolidação da estratégia de saúde da família. Cien Saude Colet 2007; 12(2):455-464.

19. Martins C, Kobayashi RM, Ayoub AC, Leite MMJ. Perfil do Enfermeiro e necessidades de desenvolvimento de competência profissional. Texto Contexto Enfermagem 2006; 15(3):472-478.

20. Siqueira MMM, Gomide Júnior S. Suporte no trabalho. In: Siqueira MMM, organizador. Medidas do Comportamento Organizacional: ferramentas de diagnóstico e de gestão. Porto Alegre: Artmed; 2008. p. 283-294.

21. Ceccim RB. Educação Permanente em Saúde: descentralização e disseminação de capacidade pedagógica na saúde. Cien Saude Colet 2005; 10(4):975986.

22. Minayo MCS. Interdisciplinaridade: funcionalidade ou utopia? Saúde e Sociedade 1994; 3(2):42-64.

23. Siqueira MMM, Padovan VAR. Bases Teóricas de Bem-Estar Subjetivo, Bem-Estar Psicológico e BemEstar no Trabalho. Psicologia: Teoria e Pesquisa 2008; 24(2):201-209.

Artigo apresentado em 31/07/2012

Aprovado em 27/01/2013

Versão final apresentada em 09/02/2013 